\title{
Capacity to Mediate and the Human Right to Self Determination: The Mediator's Responsibility!
}

\section{Mary Condell}

\begin{abstract}
The purpose of this paper is to examine capacity in a mediation context including the level of responsibility a mediator has for assessing the capacity of participants; when that assessment should be made; and whether or not there are any guiding principles available to assist mediators in making the assessment. This is carried out, by reference to the available literature, under the following headings: the human rights origins of self-determination; capacity in a mediation context; the internationally recognised approaches to capacity; the best approach to capacity for mediators; and the obligations which will be imposed on mediators working in Ireland in view of the imminent Assisted Decision Making (Capacity) Bill 2013. The paper additionally looks at the skills necessary to assess capacity in mediation and asks if mediators' training adequately provides them, and concludes that the responsibility to assess capacity to mediate rests solely with the mediator.
\end{abstract}

\section{Keywords}

Mediation, human rights, self-determination, mediator`s responsibility

\section{The Human Rights origins of Self Determination}

Article 1 of the Universal Declaration of Human Rights (1948) proclaimed that "all human beings are born free and equal in dignity and rights. They are endowed with reason and conscience and should act towards one another in a spirit of brotherhood". It follows from this that to make a judgement, or even worse, to assume that any person lacks capacity to partake in any human undertaking, may deny them their basic human rights. If so, why should any mediator, or indeed anyone else, be allowed, let alone obliged to assume an actual responsibility to do so?

The answer is that while the presumption of full decision making capacity comprised in the absolute right for all human beings to fully participate in all human undertakings and to make all decisions about him/herself and his/her life for his/herself is there for all, not all humans are capable, for an 
enormous variety of different reasons, of exercising it for themselves. This inability can be due to an inherent intellectual disability from birth. It may also be an acquired disability due to a mental illness or disorder. In the case of the elderly it can be due simply to old age or transient physical illness, or it may have been acquired as a result of a physical illness or injury, for example through stroke or brain injury following an accident. It may also be permanent or transitory. This is one aspect of capacity but, additionally, as all mediators are aware, limited capacity to self-determine may also be situational and reactive, such as extreme power differential between parties, or as a result of domestic abuse or the fear of the consequences of actions, or there may be physical impediments to effective participation in mediation such as hearing or sight loss or simply wheel chair inaccessibility. These dual aspects of the concept of capacity and how they interact and cross-relate to one another in a mediation context are discussed more fully below.

Does this therefore mean that a human being affected by any of the above is not entitled to the right mentioned in Article 1 of the UN Convention? The UN Convention on the Rights of Persons with Disabilities (UNCRPD) (2007) put this beyond doubt by clarifying that the existing body of human rights applied equally to persons with disabilities, any disability whether physical or mental. Whilst Ireland has signed this Convention, for reasons examined later, it has not yet been ratified here.

There is therefore an internationally accepted human right to participate fully in all human endeavours. It follows from this that any assessment of the capacity of any person to engage in any human endeavour, including mediation, has to be very carefully scrutinised in order to establish that there is no infringement of his/her rights.

\section{Capacity in a Mediation Context}

Where a party to a mediation has a physical disability, such as hearing loss or is a wheelchair user, those physical disabilities can and should be accommodated within the mediation process so as to respect that party's right to full participation.

This paper concerns itself in the main, however, with non-physical, and therefore less obvious disabilities such as an intellectual disability or mental condition or illness, whilst fully acknowledging that the principles articulated and the rationale behind them apply equally to parties with physical disabilities.

Capacity is defined in the Concise Oxford Dictionary (1993: 165) as "mental power, faculty or talent", in other words the mental ability to do something which inter alia refers to the ability of an individual to make their own decisions.

That ability has, as mentioned above, dual but interconnected aspects to it in law. The first aspect is the question of whether or not a person has adequate mental competence to make the decision required with such assistance as may be necessary. This mental competence includes the ability to understand the nature of the issue/s to be decided, the various options available and the ability to weigh them up against one another as well as the ability to retain all the information necessary to make the decision for long enough to reach that decision (D v R (the Deputy of S) 2010 and Beck \& Frost (2007: 
266). In addition, in a mediation context this aspect would also include the ability to understand the mediation process including the role of the mediator, Beck \& Frost (2007: 260,265).

The second but interrelated aspect of capacity in law is the ability of the decider to make his/her decision free from the "undue influence" of others. In a mediation context this aspect would include the right of a party to make decisions free from the "bullying" of others, but would also include the right of a party to decide to take into account the views/positions of the other party.

Both aspects interlock with and may be influenced by one another, for example a party with an intellectual disability may be very prone to the influence of others and a party with full mental competency may nonetheless be unable or afraid for a variety of reasons to reach a decision that is wholly theirs. Given the fundamental nature of the right of all human beings to fully participate in all human endeavours, including mediation, outlined above, it might be expected that mediation text books would, in line with all other professions which involve the assessment of capacity such as law and medicine, devote at least some space to outlining, for the assistance of mediators, whether or not, how, and at what stage they should assess the parties' capacity to mediate.

Moore (2003: 85), a seminal textbook on the process of mediation, while devoting a whole section of his book to "laying the ground work for effective mediation", does not once mention the role of the mediator in assessing the capacity of the parties to enter into the mediation process. Moore's definition of mediation does however contain the core principle of self-determination.

The MII code of Ethics and Practise (2009) mentions "self-determination" under the heading of "fundamental principles of mediation", and that it is the parties themselves who make the decisions in relation to the outcome of the mediation.

Does this mean that mediation training and the practice of mediation therefore concern themselves more with the second aspect of capacity outlined above to the neglect of the first "mental competency" aspect?

Hedeen (2003: 1) in stating, that to exercise self-determination disputants must possess the capability to participate effectively in the process suggests that this is the case.

The Law Reform Commission (LRC) (2010: 47) appear however to have viewed the dispute resolution profession's term of art, "self-determination," as comprising both aspects in concluding, that the issue of party capacity to mediate, is an aspect of self-determination relevant to all mediations.

The capacity to participate therefore, whether regarded as being comprised within the dispute resolution profession's concept of "self-determination" or not, is undoubtedly essential to the exercise of self-determination in its wider general sense, and is therefore a key concern of mediators. The challenge then is to understand by what criteria and on the basis of what evaluative methods does a mediator assess a party's capacity to participate in the process so as to ensure that their human right to fully participate and self-determine are safeguarded. 


\section{Internationally Recognised Capacity Approaches}

LRC (2006: 44) discussed the various internationally recognised approaches to capacity.

They are:

(a) The Status Approach (currently the system used by the Wards of Court in Ireland under The Lunacy Regulation (Ireland) Act 1871), is an all or nothing approach to capacity based on medical evidence only. This system, long believed to be archaic even by the judiciary (MvM 2009), LRC recognised as not meeting the requirements laid down in UNCRPD resulting in Ireland's current inability to ratify the Convention.

(b) The Outcome Approach determines capacity by the nature of the decision made by the individual, for example if the decision is regarded as "foolish" or "not a decision a normal person would make" then the person is deemed incapable.

(c) The Functional Approach is a time specific and an issue specific approach; that is, it considers firstly whether at the particular time the decision is being taken the person has the capacity to make it, and secondly whether this particular decision is a decision which the person has the capacity to make.

The questions which have to be asked of mediators, especially given that self- determination both generally and its more limited meaning for dispute resolution professionals is such a core concept in mediation, is whether and by what means mediation training familiarises mediators with these different approaches, and gives guidance about the appropriate choice of approach in a mediation context.

Crawford et al (2003: 386) suggest that mediators receive neither specific capacity training nor guidance around the correct and appropriate approach and that this has left mediators "to fend for themselves when addressing questions of party capacity, with vague notions about what to look for to determine whether mediation is appropriate". It is their view that as a result mediators have had to rely on their own personal experiences and frameworks from their professions of origin, for example for those mediators whose profession of origin is law the series of practice notes concerning elderly or vulnerable clients published by the Law Society (2008, 2009 and 2011).

Beck \& Frost, albeit writing solely in the context of divorce mediation, agree stating that mediation readiness is of particular concern in the context of compulsory court mandated mediation and that what is missing is a common standard of the minimum necessary for parties to proceed in mediation (2007: 255, 257).

This paper now seeks to offer such guidance and common standards for mediators.

\section{The Best Approach for Mediators to establish Capacity to Mediate?}

Generally, the assessment of a person's capacity to do something isn't a difficult thing to do. Most people recognise, without particular training, when a person is capable of doing something and when they are not. However, what happens for mediators when there is a doubt, such as with a person with a mental illness, a personality or learning disorder or other innate or acquired intellectual disability? 
Are such persons to be simply dismissed by the mediator as incapable of entering into the mediation process as a matter of course, or does the mediator have a duty to make further efforts to establish their capacity to mediate?

That capacity is both a grey area and may fluctuate depending on the nature of the decision to be made are concepts long recognised in law (see for example the case of Re Park (1952), in which Mr Park was found to have had the capacity to marry at 11.30 am one morning but found not to have had the capacity to make a will at $3.00 \mathrm{pm}$ the same day) and in medicine.

Wood (2003:1) recognises the fluctuating nature of capacity and also argues that, although mediators must make judgements about the understanding of the parties, there is no bright line separating capacity from incapacity. She then goes on to argue, in the context of the Americans with Disabilities Act (ADA) Mediation Guidelines published in 2000, that a mediator should not rely on either medical evidence or an adjudication of legal capacity to make their own assessment, or indeed think in terms of capacity at all, but more in terms of competency from the standpoint of whether it would be possible for the person to mediate with support. The question she suggests that mediators should ask of themselves is "what can I do to facilitate the understanding of the party" (2003: 2).

Crawford et al (2003: 386) suggest that a distinction should be made for mediators between the determination by them of capacity which implies a judgement (which would equate to either the status or outcome approach) and what they describe as a new conceptual framework to focus on "facilitating mediation competencies".

They reviewed the literature on capacity to mediate and found two assumptions emerging.

The first was that questions of capacity are limited generally to cases in which a person's psychological (including cognitive abilities) are questioned, because of either some behavioural manifestations or pre-existing information about the individual (2003: 387). The difficulty they had with this was that assessments of capacity to mediate were therefore only being made when there was some question of disability. They regarded this in itself to be discriminatory in that it focused on disempowering individuals on account of their disability, and it does fall foul of the UNCRPD principle that people with disabilities are entitled to identical treatment as others.

The second assumption they found was that a mediator "determines capacity" before beginning a mediation session and that this determination of capacity was an all or nothing approach (the status approach). They rejected this approach on the basis that a determination of capacity is such a serious deprivation of rights that it should only be made by a Judge after due process of law (2003: 391).

Quoting Wood's (2001) view that the mediation process can be adjusted to account for the need of some parties with dementia, and Nolan-Haley's (1999) belief that capacity is not a fixed condition and can be effected by a variety of settings. Crawford et al considered that she, more than anyone else, came closest to explaining how "informed consent" is related to whether or not a party has the ability to participate in mediation, when she said that the principle of informed consent "promotes respect for the fundamental value of human dignity" (2003: 389). As "informed consent" comprises both aspects of capacity outlined above, that is the mental ability aspect coupled with freedom to make a decision for 
oneself free from undue influence, it is within the wider general use of the term self-determination.

Crawford et al further point out that as discussion of the assessment of capacity in mediation usually focused only on disempowering individuals, the individual is thereby kept forever captive by the terms used to describe their incapacity. They regard this as an oversimplification and point out that, as mediation is interactive and multi- facetted, it incorporates "multiple competencies, individual and group as well as procedural or dynamic processes" and that the role of the mediator is to facilitate these multiple competencies (2003: 391). They use this term because they state that the term "competencies" suggests two things; firstly, that a person may have many abilities, and secondly an individual's ability may vary from time to time. The role of the mediator is therefore to distinguish between the person's competencies; for example, a person may have the competency to decide living arrangements but may not have the competency to enter into financial arrangements regarding them (2003: 393).

The concept too of varying ability, they argue, also places an onus on the mediator to act in a manner which enhances abilities; for example, in the case of somebody who is taking medication, to ask would their ability to partake in the process be better at one particular time of day rather than at another. They conclude that facilitating competencies defaults to inclusion in the process in a way that merely determining capacity does not (2003: 394). This in turn emphasises the mediator's primary role as that of a facilitator who acts, not as an authority over the parties as they would when make a determination of capacity, but as a catalyst for the parties to put into effect "their self- determination and collaboration competencies". The very important by- product of this is that the mediator can thereby address the power imbalance which may manifest itself if one of the mediating parties has a disability.

Furthermore, this shift in focus from detached analysis (a determination of capacity) to supportive engagement should occur not only before the mediation commences, but continually, in that the mediator is continually measuring the party's abilities as the mediation process unfolds, and then taking steps to support party behaviours that are conducive to the principles of mediation (2003: 396). In short, the mediator is doing what the mediator does anyway with people of no recognisable incapacity or disability in order to give full effect to the dual principles of self-determination and enforcement.

Porter (2003), accepting the views of Crawford et al (2003), adds that the mediator should examine the capability of a disputant to fully engage in a dynamic, facilitated and often emotionally charged process, and that this examination should include a determination of any accommodation or process adaptions that participants need to enhance their mediation capabilities. She states that "empowerment" refers to the process of "enabling disputants to gain strength and recognise their own value in order to enhance their participation in the process" (2003: 2\&3). Beck \& Frost argue that one of those process adaptions may be to allow the presence of a support person to sufficiently increase a party's functional capabilities (2007: 273).

This concept of facilitating competencies is in essence the functional test for capacity as recommended by LRC (2006) and also the "decision specific" concept recommended in the ADA Mediation Guidelines (2000). 


\section{Mediator assessment of Capacity in Irish context}

Whilst Ireland signed up to the UNCRPD in 2007, it has not yet ratified the Convention on account of the fact that Irish domestic law is not yet in general conformity with the treaty.

The need for this domestic legislation was addressed by the LRC in a series of consultation papers and reports and was also addressed in its ADR Report (2010: 47).

LRC in that Report noted that the issue of capacity is relevant to all mediations, requiring a mediator to ensure at all stages in the mediation process that a party has the capacity to engage in the process by reference to the test of capacity set out in the (then) scheme of the Mental Capacity Bill 2008 and that this reflected the international move towards the functional approach to capacity. LRC also considered it an additional duty of the mediator to assess for capacity at every stage where a party must make a decision during the process, adding that if at any point in the mediation process a party appeared to have difficulty comprehending the process, the issues or settlement options, or had difficulty actively participating in the process, that the mediator should "explore with the party the circumstances and the potential accommodations, modifications or adjustments that would enable the party's participation" (2010: 47).

This approach mirrors what Crawford et al (2003: 399) advocate when they state that facilitating competencies requires supportive engagement. Wood's (2003: 2) suggestions for supporting shifting capacity abilities, include: changing the time or place of the session, supplying a support person, keeping the sessions short or using techniques or strategies helpful for communication with persons with memory loss or confusion, were also endorsed by and quoted in LRC (2010: 47).

The legislation which will allow Ireland to ratify the UNCRPD is now known as the Assisted Decision Making (Capacity) Bill 2013 (ADMC Bill). The Scheme of the Bill was published in 2013 after which it went through a public consultancy phase. It is expected to be discussed at Committee stage in the Dáil in early 2015 .

The ADMC Bill adopts the functional approach to the assessment of any person's capacity by any other person for any purpose. It therefore applies to mediators and is legislation which it will be incumbent upon every mediator to know and apply in accordance with the Guiding Principles set out in Section 8 .

The basic capacity assessment framework it sets out includes the following:

- It shall be presumed unless the contrary is established that a person has capacity (section 8.2)

- A person shall not be treated as unable to make a decision unless all practicable steps to help him or her to do so have been taken without success (section 8.3)

- The capacity to make a decision means the ability to understand the nature and consequences of a decision (issue specific) in the context of available choices at the time the decision is to be made (time specific) (section 3.1)

- A person lacks the capacity the capacity to make the decision if he or she is unable;

a) To understand the information relevant to the decision, 
b) To retain that information,

c) To use or weigh that information as part of the process of making the decision or,

d) To communicate his or her decision (by any means) or, if the decision requires the act of a third party to be implemented, to communicate by any means with that third party (section 3.2)

- A person is not to be treated as unable to make a decision merely because he/she makes an unwise decision (section 8.4)

- A person assessing capacity is obliged, so far as is reasonably practicable, to permit, encourage and facilitate the person to participate, or to improve his or her ability to participate, as fully as possible in any act done for him or her or any decision affecting him or her (section 8.7)

- The fact that a person is unable to retain the information relevant to the decision for a short time is not to be regarded as incapacity to make the decision (section 3.3)

- The question of having capacity or not is to be decided by the assessor on the balance of probabilities (section 3.5).

Mediators will, along with all other professionals, therefore shortly have in statutory form the guidance needed on what approach should be taken in capacity assessment. Meanwhile the Bill, in the absence of any other guidance, can be used as an effective capacity assessment framework for mediators.

\section{Capacity Assessment Skills}

As a part of their "facilitating competencies" framework Crawford et al (2003: 396-397) suggest the following mediator skills or activities:

- Ongoing needs assessment

- Reflecting back to the parties what has occurred

- Discussion of the possibilities. including looking for options that open the process for parties who have special needs and not just options as part of the settlement,

- Removing barriers to party choice of options by actually asking the party what is necessary for them to make a decision

- Considering whether extra time may be needed for competency facilitation

- Balancing the cognitive and emotional components of decision making.

They argue that mediators can, in order to do this, simply call on skills they already have in their repertoire of expertise in the mediation field (2003: 398).

Craig, in an article concerning "patient decision making," argues that medical, nursing and paramedical staff should be trained in communication, negotiation or mediation skills so that they can use 
these skills in their spheres of work. She states that mediation, as a non-coercive and gentle process, is well suited to "patient decision making," as it affirms patients' self-worth and achievements by empowering them to contribute effectively to decision making about their own future (1996: 7).

She is therefore arguing that mediators, by virtue of their training, already possess the tools necessary to support people-whose decision making powers may be physically or emotionally compromised—-to make decisions.

There is no doubt that listening and questioning skills and the ability to express empathy, which are the hallmarks of the mediator, are taught to trainee mediators enabling them to enhance the capacity of mediation participants to exercise self- determination generally.

However, while these skills are undoubtedly a fundamental part of a mediator's basic "tool kit", something more is required in order to support a person in mediation whose capacity is in question, especially if that person has a recognised mental or physical disability or illness or, as in elder mediation, may be vulnerable through advanced age or dementia.

Coy and Hedeen (2000: 8) after considering two contrasting cases where mental illness and a personality disorder were encountered in mediating parties, argue that mediators trained in specialist skills and knowledge of the needs of the "disabled" community who can coordinate with other specialist services can offer a sensitive and flexible approach to the mediation process making it suitable for all citizens, even those with incapacity issues. The authors warn though that possible capacity issues are only small "red flags" because they may be only "normal" pre-mediation anxieties (2000: 6).

Porter (2003:3) speaks too of the need for the skill to identify "red flags" which might indicate that the mediator needs to work more closely with the participant to fully understand their limitations. She also speaks of the need for a specialised skill set in the mediator for detecting patterns in thought processes, behavioural cues and emotional liability.

Hedeen (2003: 2) argues that it is the ethical obligation of the mediator to adapt the process or use whatever other methods will ensure capacity while also ensuring that those needs are met through respectful screening methods.

The LRC (2010: 47) considered that a mediator must have a proper understanding of the concept of capacity and have appropriate training in screening and assessing capacity.

It follows from this that mediators must provide an opportunity for this screening in the mediation process. As well, more is expected from a mediator dealing with a party who may have issues of capacity than the exercise of "ordinary" mediation skills. To put it another way, what might be acceptable in an "ordinary" mediation where all parties have full capacity, is not good enough when dealing with a party with special capacity issues and needs.

Whether it is called the functional test for capacity, or facilitating competencies, or supporting the person through the mediation process, a person who may have capacity issues has a basic human right to expect the highest standards of mediation skills. These skills include, apart from any specialist skills needed for particular disabilities, 
- Self-awareness, that is how he/she may appear to an elderly orvulnerable person and the ability to alter or temper his/her behaviour accordingly

- An ability to consciously slow the process down and to reduce concepts and explanations and options to simple straight forward and easily understood language

- An acute awareness of his/her own personal prejudices against mental illness or incapacity

- Where the elderly is concerned an acute awareness of his/her assumptions or prejudices regarding the capacity of older participants,

- A full awareness of the role of support persons, advocates or specialist advisors including the ability to work with them

- The ability to recognise and deal with subtle undue influence which can be so prevalent with vulnerable people

- Endless patience, understanding and empathy.

\section{Conclusion}

To support the right to participate in mediation as a human endeavour and party selfdetermination in its very widest sense, a mediator must continually assess the capacity of the parties to understand the mediation process, to take part in it, to understand and contribute to the options under discussion, as well as each party's capacity to give their voluntary, freely formed and informed consent to any agreement reached.

For the mediator to simply use the status approach to assess capacity, that is to make a once and for all capacity assessment before the mediation even starts, goes completely against the other fundamental concept of mediation, namely the empowerment of individuals and the balancing of power between individuals within mediation.

The functional test for capacity or mediation readiness, described in mediation literature as facilitating or supporting a party with capacity issues throughout the mediation process, not only upholds the fundamental mediation principles of self- determination and empowerment but will shortly in Ireland be a statutory requirement for all professionals involved in assessing capacity.

Lord Justice Munby (2011: 4), a Judge of the UK Court of Protection, has spoken of the enhanced degree of protection called for when the human dignity at stake is that of someone who is disabled in some fashion. He stated that to avoid discrimination we need to treat such a person differently precisely because their situation is different to that of the "able bodied", and that the obligation to secure their essential dignity calls for a particular human empathy and concern.

The correct approach to assessing a person's capacity to mediate should therefore be viewed by the mediator, not just as one responsibility amongst many others, but as the critical task of upholding the fundamental and internationally recognised human rights of that person through enhanced mediator capacity. 


\section{References}

Assisted Decision Making (Capacity Bill), Scheme of (2013)

http:/ /www.oireachtas.ie/viewdoc.asp?DocID=24147\&\&CatID=59

Americans with Disabilities Act (1990) http://www.mediate.com/articles/adaltr.cfm

Americans with Disabilities Act Mediation Guidelines (2000)

http://www.mediate.com/articles/adaltr.cfm .

Beck C. J. A., \& Frost L. E., (2007) 'Competence as an Element of Mediator Readiness', Conflict Resolution Quarterly Volume 25 No.2 Winter

Coy, P.G., and Hedeen T. (2000) 'Disablilities and Mediation Readiness in Court- Referred cases;

Developing Screening Criteria and Service Networks.' http://www.mediate.com/articles/cohed1.cfm (originally appeared in Mediation Quarterly 1998-1999 Volume 16 Number 2)

Craig Y.J., (1996) 'Patient Decision Making: Medical Ethics.' Journal of Medical Ethics 22:164- 167

Crawford S.H., Dabney L., Filner J.M., and Maida P. (2003) From 'Determining Capacity to Facilitating

Competencies; A New Mediation Frame Work.' Conflict Resolution Quarterly Volume 20 No. 4 Summer.

D v R (the Deputy of S) (2010 EWHC 2405 (CoP) available at

http://www.bailii.org/ew/cases/EWCOP/2010/2405.htmlHedeen T. (2003) 'Ensuring Self

Determination Through Mediator Readiness; Ethical Considerations.'

http://www.mediate.com/articles/hedeenT1.cfm.

Law Reform Commission (2010) 'Report on Alternative Dispute Resolution: Mediation and Conciliation.' LRC 98-2010

Law Reform Commission (2006)' Report on Vulnerable Adults and the Law; Capacity', LRC 83/2006

Law Society (2013) A Guide to Good Professional Conduct for Solicitors 3rd edition Dublin: Law Society of Ireland

Law Society Gazettes, December 2008 page 63, January/February 2009 page 48, April 2009

page 54, July 2009 page 44, January/February 2011 page 48

M V M 2009 IEHC 490

MII Code of Ethics and Practise. http://www.themii.ie/code-of-ethics.html Moore, C.W. (2003) The

Mediation Process. San Francisco: Jossey- Bass

Munby J., (2011) 'At what point is safeguarding abuse'. An Address delivered to an Action on Elder

Abuse Conference: The Role of Lawyers in Safeguarding Adults available at

www.solicitorsfortheelderly.com

Nolan-Haley, J.M. (1999) 'Informed Consent in mediation: A guiding principle for the Truly Educated

Decision-making'. Notre Dame Law review, 775

Porter P. (2003) 'Maximising Effective Participation' http://www.mediate.com/articles/porterP1.cfm

Re Park 19532 All England Reports 1411

The Concise Oxford Dictionary (1991) $8^{\text {th }}$ Edition London; BCA

The United Nations Convention on the Rights of persons with Disabilities (2007). 
http://www.un.org/disabilities/convention/conventionfull.shtml

Universal Declaration of Human Rights (1948). http://www.cirp.org/library/ethics/UN- human/

Wood E. (2003) 'Addressing Capacity; What is the role of the Mediator?'

http://www.mediate.com/articles/woodE1.cfm.

Mary Condell is a practicing solicitor with Sheil Solicitors in Dublin and also has her own mediation practice Equitable Solutions. Since her initial mediation training in 2007 she has worked as a mediator with a particular interest in family disputes in the area of the administration of trusts and estates and vulnerable adults, which is also the area of law in which she specialises. She has a Master's Degree in Mediation and Conflict Intervention from NUI Maynooth. She lectures regularly for the Law Society and other professional bodies on both legal and mediation issues, including designing and delivering a module for trainee solicitors on Advocacy in Mediation. She is a member and former chair of the Irish branch of the Society of Trusts and Estate practitioners (STEP) for which she prepared a mediation DVD. She is co- founder and chair of Solicitors for the Elderly (SFE) in Ireland and has given training courses in mediation skills to SFE members in Ireland and the UK. She is a member of the Law Society's Task Force on Mental Capacity which was established to review and make submissions on new capacity legislation and is legal advisor for Sage - Support and Advocacy Service for Older People. 